Received 00th January 20xx, Accepted 00th January 20xx DOI: $10.1039 / x 0 x \times 00000 x$

\section{Direct biocatalysed synthesis of first sulfur-, selenium- and tellurium- containing L-ascorbyl hybrid derivatives with radical trapping and GPx-like properties}

Damiano Tanini,* Beatrice Lupori, Gianni Malevolti, Moira Ambrosi, Pierandrea Lo Nostro, Antonella Capperucci*
6-O-L-ascorbyl selenoesters, thioesters and telluroesters can be efficiently and directly prepared from L-ascorbic acid and suitable functionalised chalcogenoesters through lipase-catalised transesterification reactions. Novel synthesised L-ascorbyl derivatives exhibited remarkable chain breaking and glutathione peroxidase-like activities.

L-ascorbic acid (vitamin C) is a powerful water soluble antioxidant essential for the correct functioning of the body, being involved in a number of biological processes ranging, amongst others, from the biosynthesis of collagen ${ }^{1}$ and catecholamine to the modulation of neurotransmission. ${ }^{2}$

The enhanced concentration of harmful reactive oxygen species (ROS) has long been related with the onset of several human diseases such as cancer, immune disorders, cystic fibrosis, and neurodegenerative deseases. ${ }^{3}$ Liposoluble vitamin $\mathrm{E}$ and hydrosoluble vitamin $\mathrm{C}$, together with phenolic compounds, carotenoids, and trace elements such as zinc and selenium are the main exogenous defences against oxidative stress. In this context, the design and the development of novel antioxidants have been attracting growing interest over the last decades. ${ }^{4}$ Particularly, owing to their capability to mimic the glutathione peroxidase enzymatic activity, the synthesis of chalcogen-containing antioxidants has recently attracted growing attention. Furthermore, organochalcogenides can possess anticancer, antibacterial, and enzyme inhibitor activities. ${ }^{5}$ The functionalization of bioactive natural products with chalcogens represents an effective strategy to modulate or improve their biological properties. For example, the introduction of chalcogencontaining moieties onto natural compounds such as tocopherols, ${ }^{6,7}$ tocotrienols, ${ }^{7}$ retinol, ${ }^{8}$ hydrxytyrosol, ${ }^{9}$ chrysin, ${ }^{10}$ quercetine, $^{10 a}$ and resveratrol ${ }^{10 c}$ have been extensively studied. However, whilst sulfur-, selenium-, or telluriumfunctionalised vitamin $\mathrm{E}$ and vitamin $\mathrm{A}$ derivatives have been reported, to the best of our knowledge the synthesis of

University of Florence, Department of Chemistry "Ugo Schiff", Via della Lastruccia 13, I-50019 Sesto Fiorentino, Italy

Electronic supplementary information (ESI) available: Full experimental details and products characterisation. See DOI: 10.1039/x0xx00000x chalcogen-containing vitamin $C$ derivatives has never been described. The paucity of such results is reasonably due to the instability of the L-ascorbic acid core, which easily undergoes oxidation of the enediol moiety and ring opening of the lactone ring. Furthermore, several alcohol protecting group strategies cannot be applied since the conditions of the endgame protecting group cleavage are often not compatible with chalcogens or with the L-ascobic acid core. For example, because the presence of chalcogens poisons the Pd-catalyst, ${ }^{11}$ the most commonly employed benzyl protecting group cannot be cleaved under mild $\mathrm{Pd} / \mathrm{C}$ catalysed hydrogenation conditions. Additionally, harsh bases- or acid-mediated deprotection procedures cause severe products decomposition.

We sought to approach this problem from a different perspective and evaluated the possibility of applying lipase biocatalysed transesterifications ${ }^{12}$ of chalcogen-containing esters and L-ascorbic acid. This approach would ideally allow a straightforward access to chalcogen-containing L-ascorbic acid derivatives, without requiring tedious and detrimental protection/deprotection steps. Lipase B catalysed transesterification is indeed a versatile tool to synthesise Lascorbyl esters under green and mild conditions. ${ }^{13}$ However, to the best of our knowledge, its application to chalcogencontaining acyl donors has never been described and its feasibility and functional group tolerance were not obvious.

We commenced our studies by establishing the optimal conditions required to promote the biocatalysed transesterification reaction of $\beta$-selenoester $\mathbf{2 a}$, prepared through seleno-Michael addition from benzeneselenol 1a and methyl acrylate (see ESI), with L-ascorbic acid $\mathbf{3}$.

According to a literature survey, the optimal temperature for the enzyme activity was established to be $45^{\circ} \mathrm{C}$. Polar solvents, such as acetone and tertiary alcohols are the media of choice for lipase-catalysed L-ascorbic acid esterifications. ${ }^{12,13}$ In our hands, acetone proved to be the most effective, plausibly owing to the high capability to dissolve both $\mathbf{2 a}$ and $\mathbf{3}$. Evaluation of different solvents commonly used for Lipase B catalysed reactions, such as tert-butanol and 2-methyl-1butanol gave lower yields. Thus, we investigated the effect of 
the reaction stoichiometry and the amount of lipase. We found that, whilst poor yields were achieved by using 500 $\mathrm{U} / \mathrm{mmol}$ of enzyme (Table 1 , entries $1-3$ ), a doubling of the enzyme amount brought about a significant yield improvement (Table 1, entry 4).

The optimal reaction time was found to be $48 \mathrm{~h}$, as partial decomposition of the reaction product was observed after 72 $\mathrm{h}$ (Table 1, entry 5). On the other hand, shorter times resulted in much lower yields (Table 1 , entry 6). Pleasingly, we found that by using an excess of $\beta$-selenoester $2 \mathbf{a}$ the desired 6-O-Lascorbyl ester 4 a was formed in rather good yield for this type of biocatalysed transformations (45\%, Table 1 , entry 8 ).

Remarkably, a significant improvement in yield was achieved upon performing the reaction in the presence of $4 \mathrm{~A}$ molecular sieves (Table 1, entries 9 and 10). Particularly, by using an excess of $\mathbf{2 a}$ under these conditions, the ascorbyl derivative $\mathbf{4 a}$ was formed in $74 \%$ yield, which represents an excellent results for lipase-catalysed transesterification reactions. The striking effect of zeolites can be reasonably ascribed to the trapping of both $\mathrm{MeOH}$ and $\mathrm{H}_{2} \mathrm{O}$. Indeed, the removal of methanol produced by the transesterification displaces the equilibrium of the reaction toward the formation of $\mathbf{4 a}$. Furthermore, by trapping water, molecular sieves hamper the competitive lipase-catalysed hydrolysis of $\mathbf{4 a}$.

Table 1. Optimization of the biocatalysed synthesis of selenium-containing 6-O-ascorbyl ester $\mathbf{4 a}$.

\begin{tabular}{|c|c|c|c|c|c|c|c|c|c|}
\hline Entry & $2 \mathbf{a}$ (Equiv.) & Lipase $B$ (U/mmol) & Time (h) & Yield (\%) $)^{a}$ & Entry & $2 \mathrm{a}_{\text {(Equiv) }}$ & Lipase $B$ (U/mmol) & $\operatorname{Time}_{(\mathrm{h})}$ & Yield \\
\hline 1 & 1.0 & 500 & 48 & 12 & 6 & 0.3 & 1000 & 24 & $<10$ \\
\hline 2 & 0.5 & 500 & 48 & $<10$ & 7 & 1.0 & 1000 & 48 & 26 \\
\hline 3 & 0.3 & 500 & 48 & $<10$ & 8 & 3.0 & 1000 & 48 & 45 \\
\hline 4 & 0.3 & 1000 & 48 & 22 & 9 & 3.0 & 1000 & 48 & $74^{c}$ \\
\hline 5 & 0.3 & 1000 & 72 & $14^{b}$ & 10 & 0.3 & 1000 & 48 & $32^{c}$ \\
\hline
\end{tabular}

${ }^{a}$ Isolated yield is reported; ${ }^{b}$ Partial decomposition of 4 a was observed; ${ }^{c} 4$ A molecular sieves $(300 \mathrm{mg}$ ) were added. See ESI for details.

Having identified optimal reaction conditions, we then proceeded to investigate the scope of the transformation with respect to different chalcogen-containing esters. Thus, a large variety of differently substituted selenium-, sulfur-, and tellurium-containing esters (Schemes 1 and S1, ESI) was synthesised as reported in the Scheme 1. $\beta$-Arylseleno- and $\beta$ alkylseleno-esters 2a-g were smoothly achieved through a novel seleno-Michael addition ${ }^{14}$ involving suitable aryl- or alkyl-selenols ${ }^{15} 1$ and methyl acrylate. The reaction occurred under very mild conditions in the presence of $\mathrm{Al}_{2} \mathrm{O}_{3}$ (Schemes 1 and S1, via A). Furthermore, $\alpha$-selenoesters $2 \mathbf{h}, \mathbf{i}$ and $\gamma$ selenoester $\mathbf{2} \mathbf{j}$ were easily obtained by exploiting the reactivity of selenols 1 with methyl bromoacetate and ethyl 4bromobutyrate, respectively (Schemes 1 and S1, via $B$ ). Similarly, variously substituted and functionalised $\alpha-, \beta-$, and $\gamma-$ thioesters 6a-i were prepared from the corresponding aryl or alkyl thiols and suitable electrophiles (Scheme S1, via $A$ and via
$B$ ). Disulfide $\mathbf{6 j}$, bearing two ester functions and four sulfur atoms, was synthesised from 1,9-nonanethiol through a twostep procedure involving a thio-Michael addition and a DCF (dicyanofumarate) mediated oxidation sequence (see ESI for details). ${ }^{16}$ Finally, $\beta$-aryltelluroesters $\mathbf{8} \mathbf{a}, \mathbf{b}$ were prepared from the corresponding ditellurides and methyl 3-bromopropionate (Scheme 1 and S1).

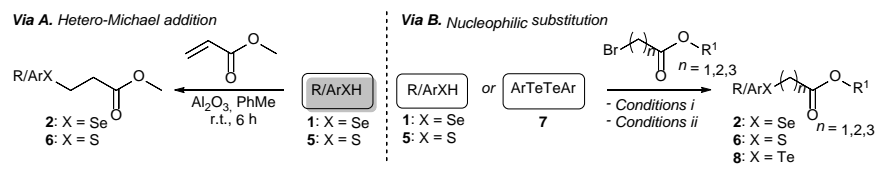

Via $B$, reagents and conditions. Conditions $i$ : R/ArSH 1 or $\mathrm{R} / \mathrm{ArSeH} 5$ (1.0 eq.), $\mathrm{Cs}_{2} \mathrm{CO}_{3}$ (1.0 eq.), TBAI (1.0 eq.), dry DMF, $0^{\circ} \mathrm{C}$, bromoester (1.1 eq.), then $0^{\circ} \mathrm{C}$ to r.t. for $4 \mathrm{~h}$; Conditions ii: ArTeTeAr 7 (1.0 eq.), $\mathrm{NaBH}_{4}$ (3.0 eq.), $0^{\circ} \mathrm{C}$ for $30 \mathrm{~min}$, bromoester (2.2 eq.), then $0^{\circ} \mathrm{C}$ to r.t. for $4 \mathrm{~h}$. See ESI for details

Scheme 1 . Synthesis of selenoesters 2 , thioesters $\mathbf{6}$, and telluroesters 8 .

Having in hands a wide range of differently substituted and functionalised chalcogen-containing esters, we then explored the scope of the lipase-catalysed transesterification reaction with L-ascorbic acid (Scheme 2). Under the optimised reaction conditions, $o_{-}^{-}, m-$, and $p$-methoxy phenylselenoesters $\mathbf{2 b - d}$ gave selectively the corresponding 6-O-ascorbyl arylselenoalkanoates $\mathbf{4 b}$-d in good yield. $\beta$-Selenoester $\mathbf{2 e}$, bearing a $p-\mathrm{F}_{-} \mathrm{C}_{6} \mathrm{H}_{4}$ ring, also reacted efficiently with 3 to afford compound $\mathbf{4 e}$. The biocatalysed transesterification reaction was also successfully applied to the synthesis of L-ascorbyl derivatives $\mathbf{4 f , g}$ bearing different alkylseleno moieties, including the functionalised glycidol derivative (4g). Furthermore, methyl and ethyl $\alpha$ - and $\gamma$-selenoesters $\mathbf{2} \mathbf{h}$-j were efficiently transesterified with $\mathbf{3}$ yielding the corresponding 6$\mathrm{O}$-L-ascorbyl esters $\mathbf{4 h}$-j in rather good yields, therefore demonstrating the versatility of the biocatalysed approach towards the synthesis of variously functionalised homologous L-ascorbyl selenoesters.

Next, we turned our attention to evaluating the generality of such reaction with respect to sulfur-containing esters. $\beta$ Arylthioesters 6a-d were smoothly converted into the corresponding sulfurated 6 - $O$-ascorbyl derivatives bearing a phenyl ring (9a) or $o^{-}(\mathbf{9 b}), m-(9 c)$, and $p$ - (9d) bromosubstituted benzenes bonded to the $\mathrm{S}$ atom. This methodology could also be applied to more interesting highly functionalised alkyl sulfides. The hydroxy-substituted S-alkyl $\beta$-thioester 6e and the enantioenriched epichlorohydrin derivatives (S)-6f and $(R)$-6f were successfully transferred onto the L-ascorbic acid core, affording the corresponding functionalised ester $\mathbf{9 e}$ and the enantioenriched derivatives $\mathbf{9 f}$ and $\mathbf{9 g}$, containing three controlled stereogenic centers and the further functionalisable chlorinated chain. Additionally, chiral enantioenriched $N$-Tosyl amino-substituted $\beta$-thioester $\mathbf{6 g}$, synthesised from Lvaline, ${ }^{14,15 a}$ could be efficiently employed to access the enantioenriched S, $\mathrm{N}$-containing 6-O-L-ascorbyl ester $\mathbf{9 h}$. 


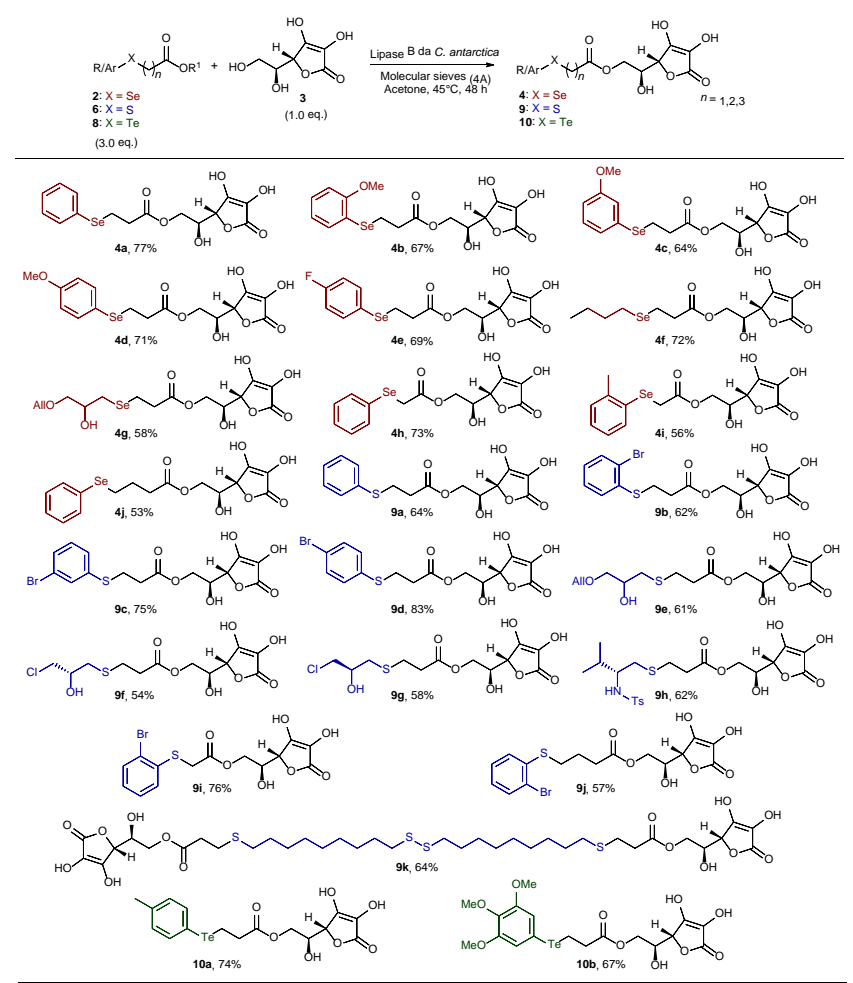

Scheme 2. Biocatalysed direct synthesis of selenium-, sulfur-, and tellurium-containing 6-O-ascorbyl esters 4, 9, 10 from Lascorbic acid. Isolated yields are reported.

Furthermore, also $\alpha$ - and $\gamma$-thioesters $9 \mathbf{i}$ and $9 \mathbf{j}$ were conveniently achieved treating $\mathbf{3}$ with $\mathbf{6 h}$ and $\mathbf{6 j}$, respectively, under the above described conditions. Remarkably, the disulfide $\mathbf{6 j}$ was successfully used in a double biocatalysed transesterification to afford the potentially valuable bola type bis-ascorbyl ester $\mathbf{9 k}$, bearing two L-ascorbyl moieties and four sulfur atoms. Indeed, owing to the unique physicochemical properties of bola type structures, novel bifunctional chalcogen-containing amphiphilic ascorbic acid derivatives could find wide application both in polymers and material sciences and in medicinal chemistry for the drug delivery of lipophilic molecules. ${ }^{12 a, 17}$

Finally, in order to enlarge the scope of this methodology to organotellurium derivatives, we evaluated the reactivity of $\beta$ aryltelluroesters $\mathbf{8} \mathbf{a}, \mathbf{b}$ with $\mathbf{3}$. Under the optimised reaction conditions, 6-O-L-ascorbyl aryltelluroalkanoates $10 \mathbf{a}, \mathbf{b}$ were directly and selectively formed in good yield, thus highlighting the remarkably broad scope of the procedure and the possibility to use the lipase-catalysed approach with all chalcogens.

Owing to the presence of both the vitamin $C$ free enediol moiety and the selenium or tellurium atom, ascorbyl derivatives $\mathbf{4}$ and $\mathbf{1 0}$ can exhibit both chain breaking and catalytic antioxidant activities, therefore representing excellent antioxidant candidates. Having developed a convenient procedure to access novel chalcogen-containing Lascorbic acid derivatives, we wished to investigate their antioxidant properties. Pleasingly, according to the DPPH assay, all the synthesised 6-O-ascorbyl esters exhibited remarkable chain breaking activity, ${ }^{18}$ leading to a rapid free radical quenching (complete decolouration of ethanolic DPP. solution occurred within 3 seconds) and, thus, showing radical scavenger properties comparable to those of L-ascorbic acid, which represents the most powerful hydrophilic antioxidant. Furthermore, the catalytic thiol peroxidase like activity of selected L-ascorbyl derivatives was also pursued according to literature reported methods using dithiothreitol (DTT) ${ }^{19}$ or glutathione $(\mathrm{GSH})^{19}$ as substrates (see Scheme S2 and Fig. S2, S3). We were delighted to discover that all tested seleniumand tellurium-contained vitamin $\mathrm{C}$ derivatives behave as catalysts in promoting the reduction of hydrogen peroxide in the presence of a thiol cofactor (Table 2). Intriguingly, when the DTT oxidation assay is accomplished using 1.0 eq. of hydrogen peroxide ca. $20 \%$ of DTT remained unreacted, thus demonstrating that the reaction of $\mathrm{H}_{2} \mathrm{O}_{2}$ with the enediol moiety occurs faster with respect to the oxidation of the chalcogen atom, which represents the first step of the GPx-like catalytic cycle. On the other hand, complete DTT oxidation was achieved upon using an excess (1.2 eq.) of $\mathrm{H}_{2} \mathrm{O}_{2}{ }^{20}$ As can be noticed (Table 2 and Figure 1), under these conditions all the tested compounds exhibited catalytic thiol-peroxidase like properties, being able to promote the oxidation of both DTT and GSH. Intriguingly, the $\beta$-alkylselenoester $\mathbf{4 g}$ showed higher catalytic activity with respect to the arylseleno-substituted analogues $\mathbf{4 a - c , e . ~ F u r t h e r m o r e , ~ a c c o r d i n g ~ t o ~ b o t h ~ a s s a y s , ~ L - ~}$ ascorbyl $\beta$-aryltelluroalkanoates $\mathbf{1 0 a}, \mathbf{b}$ behaved as more effective catalysts with respect to the similar seleniumcontaining derivatives 4a-e. Furthermore, particularly interesting are the results obtained through the GSH/GR/NADPH coupled test, that better reproduces the cellular environment (Figure 1). Indeed, under these conditions the novel synthesised L-ascorbyl derivatives exhibited GPx-like activity, thus demonstrating the effective enhanced antioxidant properties of these novel amphiphilic systems, thus offering new opportunities for their potential wide application in chemistry, biology, and materials science.

Table 2. Thiol-peroxidase like activity of selenium- and tellurium-containing 6-O-L-ascorbyl esters $\mathbf{4}$ and $\mathbf{1 0}$ according to DTT and GSH/GR methods

\begin{tabular}{clll}
\hline Entry & Compound & DTT $\left(T_{50}\right)^{a, b}$ & GSH/GR $\left(T_{50}\right)^{a, c}$ \\
\hline 1 & 4a & $3405( \pm 268)$ & $43( \pm 5)$ \\
2 & 4b & $4270( \pm 325)$ & $48( \pm 7)$ \\
3 & 4c & $4046( \pm 314)$ & $45( \pm 5)$ \\
4 & 4e & $3862( \pm 362)$ & $53_{( \pm 4)}$ \\
5 & 4g & $1346( \pm 151)$ & $37( \pm 3)$ \\
6 & 4h & $2846( \pm 116)$ & $42^{( \pm 6)}$ \\
7 & 10a & $654( \pm 104)$ & $18( \pm 3)$ \\
8 & 10b & $386_{( \pm 93)}$ & $14( \pm 3)$ \\
\hline
\end{tabular}

${ }^{a} T_{50}$ is the time required, in seconds, to halve the initial thiol concentration after the addition of $\mathrm{H}_{2} \mathrm{O}_{2}$; data in parenthesis are the experimental error. ${ }^{b} \mathrm{DTT}$ oxidation was monitored by the mean of ${ }^{1} \mathrm{H}$ NMR spectroscopy; $10 \mathrm{~mol} \%$ of 4 and $1 \mathrm{~mol} \%$ of $\mathbf{1 0}$ were used. 'NADPH consumption was monitored by UV spectroscopy $(340 \mathrm{~nm})$. 


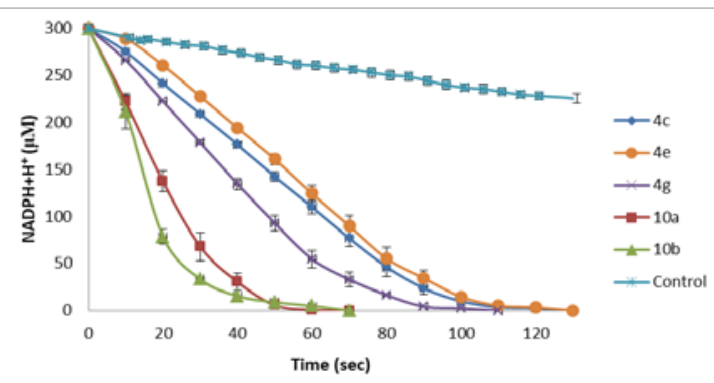

Figure 1. NADPH-coupled GPx assay. Reaction conditions: $[\mathrm{NADPH}]_{0}=0.3 \mathrm{mM},[\mathrm{GSH}]_{0}=1.0 \mathrm{mM},\left[\mathrm{H}_{2} \mathrm{O}_{2}\right]_{0}=2.5 \mathrm{mM},[\mathrm{GR}]$ $=4$ units per $\mathrm{mL}$, [catalyst] $=0.1 \mathrm{mM}$ in $\mathrm{pH} 7.4$ phosphate buffer at ambient temperature. The mean \pm SD values of three separate experiments are reported.

Preliminary physicochemical characterisation of these novel amphiphilic antioxidants showed that most of them behave as semicrystalline solids. The evolution of the crystal and of the amorphous fraction depends on the thermal history of the sample, a common behaviour of polymers. The DSC curves obtained for $9 \mathrm{c}$ are reported in Fig. S1 (see ESI). The crystalline fraction in 9c melted at about $75^{\circ} \mathrm{C}$ producing an endothermic peak with $\Delta \mathrm{H}=21.6 \mathrm{~J} / \mathrm{g}$. When the melt was slowly cooled to $20{ }^{\circ} \mathrm{C}$ (at $5{ }^{\circ} \mathrm{C} / \mathrm{min}$ ), crystallisation occurred producing an exothermic peak at about $35.5{ }^{\circ} \mathrm{C}$ with $\Delta \mathrm{H}=28.2 \mathrm{~J} / \mathrm{g}$. The crystalline fraction was found to melt between $40{ }^{\circ} \mathrm{C}$ and 100 ${ }^{\circ} \mathrm{C}$ upon heating. Instead, when the sample was cooled quickly down to $-20{ }^{\circ} \mathrm{C}$ (at $50{ }^{\circ} \mathrm{C} / \mathrm{min}$ ), no crystallisation was shown, and a cold crystallisation exothermic peak was detected in the following heating cycle followed by a broad endothermic melting peak. Remarkably, while this behaviour is typical for polymers, it is rather unusual for such small molecules as those synthesized in the present work and may represent an opportunity for their application in material science.

In summary, we have found a convenient, green, mild, and direct route to synthesise novel chalcogen-containing Lascorbyl derivatives. Such compounds would not have been accessible through classic methodology. Owing to their enhanced chain breaking and catalytic antioxidant properties, these conjugate molecules represent potential valuable systems in biology and in medicinal chemistry.

\section{Conflicts of interest}

There are no conflicts to declare.

\section{Notes and references}

1 R. S. Pinnell, Yale J Biol Med., 1985, 58, 553.

2 R. Figueroa-Méndez and S. Rivas-Arancibia, Front. Physiol., 2015, 6, 397.

3 (a) J. K. Andersen, Nat. Rev. Neurosci., 2004, 5, S18; (b) R. C. S. Seet, C.-Y. J. Lee, E. C. H. Lima, J. J. H. Tan, A.M. L.Quek, W.-L. Chong,W.-F. Looi, S.-H. Huang, H. Wang, Y.-H. Chand and B. Halliwell, Free Radical Biol. Med., 2010, 48, 560.

4 (a) S. Yoshida, F. Kumakura, I. Komatsu, K. Arai, Y. Onuma, H. Hojo, B. G. Singh, K. I. Priyadarsini and M. Iwaoka, Angew.
Chem., Int. Ed., 2011, 50, 2125; (b) C. W. Nogueira, G. Zeni and J. B. T. Rocha, Chem. Rev., 2004, 104.

5 (a) A. R. Patra, S. S. Roy, A. Basu, A. Bhuniya, A. Bhattachariee, S. Hajra, U. H. Sk, R. Baral and S. Bhattacharya, Sci. Rep., 2018, 8, 2194; (b) A. Angeli, D. Tanini, A. Capperucci and C. T. Supuran, Bioorg. Chem., 2018, 76, 268; (c) A. Angeli, D. Tanini, A. Capperucci, G. Malevolti, F. Turco, M. Ferraroni, C. T. Supuran, Bioorg. Chem., 2018, 81, 642; (d) A. Angeli, D. Tanini, A. Capperucci and C. T. Supuran, ACS Med. Chem. Lett., 2017, 8, 1213.

6 (a) V. P. Singh, J. F. Poon and L. Engman, Org. Lett., 2013, 15, 6274.

7 P. S. Vraka, C. Drouza, M. P. Rikkou, A. D. Odysseos and A. D. Keramidas, Biorg. Med. Chem., 2006, 14, 2684.

8 S. C. Welch and M. Gruber, J. Med. Chem., 1979, 22, 1532.

9 G. Rodríguez-Gutiérrez, F. Rubio-Senent, A. Gómez-Carretero, I. Maya,JJ. Fernández-Bolaños, G. G. Duthie and B. de Roos, Eur. J. Nutr., 2018, doi: 10.1007/s00394-018-1733-y.

10 (a) S. F. Fonseca, D. B. Lima, D. Alves, R. G. Jacob, G. Perin, E. J. Lenardão and L. Savegnago, New J. Chem., 2015, 39, 3043; (b) I. L. Martins, C. Charneira, V. Gandin, J. L. Ferreira da Silva, G. C. Justino, J. P. Telo, A. J. S. C. Vieira, C. Marzano and A. M. M. Antunes, J. Med. Chem., 2015, 58, 4250; (c) D. Tanini, L. Panzella, R. Amorati, A. Capperucci, E. Pizzo, A. Napolitano, S. Menichetti and M. d'Ischia, Org. Biomol. Chem., 2015, 13, 5757.

11 P. Albers, J. Pietsch and S. F. Parker, J. Mol. Catal. A: Chem., 2001, 173, 275.

12 (a) C. Dolle, P. Magrone, S. Riva, M. Ambrosi, E. Fratini, N. Peruzzi and P. Lo Nostro, J. Phys. Chem. B, 2011, 115, 11638; (b) G. Carrea and S. Riva, Angew. Chem. Int. Ed., 2000, 39, 222

13 (a) K. Nott, A. Brognaux, G. Richard, P. Laurent, A. Favrelle, C. Jérôme, C. Blecker, J. P. Wathelet, M. Paquot and M. Deleu, Prep. Biochem. Biotechnol., 2012, 42, 348; (b) S. Park, F. Viklund, K. Hulta and R. J. Kazlauskas, Green Chemistry, 2003, 5, 715

14 D. Tanini, S. Scarpelli, E. Ermini, A. Capperucci, Adv. Synth. Catal., 2019, DOI 10.1002/adsc.201900168

15 (a) D. Tanini, C. Tiberi, C. Gellini, P. R. Salvi, A. Capperucci, Adv, Synth. Catal., 2018, 360, 3367; (b) A. Angeli, D. Tanini, A. Nocentini, A. Capperucci, M. Ferraroni, P. Gratteri and C.T. Supuran, Chem. Commun., 2019, 55, 648.

16 G. Mlostoń, A. Capperucci, D. Tanini, R. Hamera-Fałdyga and H. Heimgartner, Eur. J. Org. Chem., 2017, 6831

17 S. Palma, R.H. Manzo, P. Lo Nostro and D. Allemandi, Int. J. Pharm. 2007, 345, 26.

18 (a) E, Tempestini, M. Bucci, V. Mastromartino, M. Gori, D. Tanini, M. Ambrosi, E. Fratini, A. Capperucci and P. Lo Nostro, ChemPhysChem 2017, 18, 1400; (b) P. Lo Nostro, G. Capuzzi, A. Romani and N. Mulinacci, Langmuir, 2000, 16, 1744.

19 (a) D. Tanini, A. Grechi, L. Ricci, S. Dei, E. Teodori, A. Capperucci, New J. Chem., 2018, 42, 6077; (b) F. Kumakura, B. Mishra, K. I. Priyadarsini and M. Iwaoka, Eur. J. Org. Chem., 2010, 440.

20 A reasonable catalytic cicle is the following. Ring opening of the oxidised lactone ring cannot be ruled out. See: J. C. Deutsch, Anal. Biochem., 1998, 255, 1.

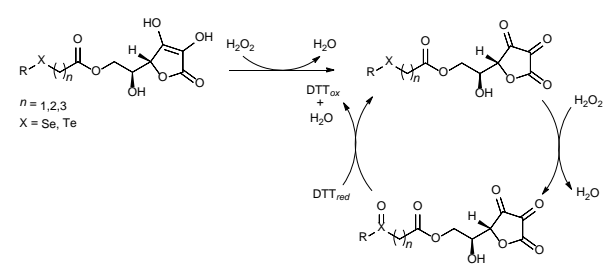

